\title{
Forecasting Spare Part Demand with Installed Base Information: a Review
}

\author{
Sarah Van der Auweraer ${ }^{\mathrm{a}}$, Robert Boute ${ }^{\mathrm{a}, \mathrm{b}}$, Aris Syntetos ${ }^{\mathrm{c}}$ \\ ${ }^{a}$ Research center for Operations Management, Faculty of Business and Economics KU Leuven, Belgium \\ ${ }^{b}$ Technology $\&$ Operations Management Area, Vlerick Business School, Belgium \\ ${ }^{c}$ Cardiff Business School, Cardiff University, United Kingdom
}

\begin{abstract}
The classical spare part demand forecasting literature studies methods to forecast intermittent demand. The majority of these methods do not consider the underlying demand generating factors. Demand for spare parts originates from the part replacements of the installed base of machines, which are either done preventively or upon breakdown of the part. This information from service operations, which we refer to as installed base information, can be used to forecast future spare part demand. In this paper we review the literature on the use of such installed base information for spare part demand forecasting to asses (1) what type of installed base information can be useful; (2) how this information can be used to derive forecasts; (3) what is the value of using installed base information to improve forecasting; and (4) what are the limits of the currently existing methods. The latter serve as motivation for future research.

Keywords: Spare parts, demand forecasting, literature review, maintenance, installed base
\end{abstract}

\section{Introduction}

Service maintenance is commonly used to extend the lifetime of capital assets, such as manufacturing equipment or heavy infrastructure, often referred to as the installed base. It is performed when a component breaks down and needs replacement, or the maintenance and part replacement can be performed preventively. The former type of service maintenance is known as corrective maintenance, whereas the latter is known as preventive maintenance. When the spare parts necessary to perform the maintenance action (also denoted as the service parts), are not available, the incurred shortage costs may be substantial. For instance, the unavailability of a machine part could jeopardize the productivity of a plant, inducing large time delays and thus high costs. For this reason, companies often keep stock buffers to deal with the uncertain demand of these spare parts. Having extra safety stocks on an individual stock keeping unit (SKU) basis may not necessarily be a problem: a small amount of additional stock might be sufficient to provide a good service level. However, even if only one extra unit of stock is held for many hundreds or thousands of items, this results in considerable amounts of capital tied up in safety stocks. It is common to observe companies of moderate size carrying thousands of different items in inventory, resulting in excessive holding costs (e.g., Güvenir \& Erel, 1998). Donnelly (2013) described Maintenance, Repair and Operations inventories to account for up to $40 \%$ of the annual procurement budget in 
many organizations. Clearly, a trade-off exists here between the investment in inventories and the observed shortages. This trade-off can be translated to balancing inventory costs and the attained service level. Specialized service parts models should therefore focus on improving the availability of parts whilst limiting the investment in inventories.

Spare part demand is known to be intermittent (Dekker et al., 2013). In the literature, specific techniques have been developed to forecast intermittent spare part demand (for an overview, we refer to Syntetos et al. (2009a); Boylan \& Syntetos (2010); Bacchetti \& Saccani (2012)). However, these methods are mostly time series based, i.e., they rely on the historical demand pattern to generate demand forecasts, but do not take into account the factors that generate the spare parts demand. Indeed, the demand for spare parts originates from the part replacements of the installed base of machines (either preventively or correctively). We refer to the factors regulating the spare part demand (i.e., the failure behavior of the components, the maintenance policy, etc.) as the installed base information.

The installed base of a product is the number of sold products that can lead to demand of their spare parts (Kim et al., 2017). Dekker et al. (2013) stress the importance of knowing the characteristics of this installed base (e.g., age, usage) to make correct inventory decisions. Fortuin (1984) claims that using installed base information to forecast spare part demand can lead to up to $25 \%$ stock reductions. Auramo \& Ala-risku (2005) suggest to additionally use information on the sudden and scheduled service needs of the products in the decision making process. Over time, a number of papers have been published that exploit this link between the part replacements and the demand for spare parts to forecast future spare part demand, each with its own assumptions. In this article, we review the literature on the use of installed base information for forecasting such demand.

Our work contributes to the growing body of literature reviews on spare part demand forecasting along the following lines. Babiloni et al. $(2010)$ provide a review on intermittent demand forecasting, whereas Boylan \& Syntetos (2010), Rego \& Mesquita (2011), and Bacchetti \& Saccani (2012) review the literature on spare parts demand forecasting specifically. The focus mainly lies on techniques based on historical demand data, and the authors hardly consider other sources of information. The work by $\mathrm{Hu}$ et al. (2017) presents a framework for operational research in spare parts management. This paper does take into account other factors than the time series data alone. The authors touch upon reliability based forecasting, taking into account the failure rate of the parts, the influence of the operating environment on the reliability characteristics, and the impact of different maintenance strategies, but they do not consider the impact of the evolution and status of the installed base explicitly. There also exists a review that addresses installed base information as a source of information for industrial services (Perminova-Harikoski et al. 2015), yet with no focus on its use for spare part demand forecasting. To the best of our knowledge, our review is the only one that is dedicated to the use of installed base information to forecast spare part demand. With our work, we provide the academic community with a review on literature concerning the use of installed base information for forecasting. We clarify what type of installed base information can be useful, how this information can be used to produce spare part demand forecasts, and what is the value of using installed base information to improve forecasting. Lastly, we also consider the limits of the currently existing methods, in order to provide a foundation for future research.

The remainder of the paper is organized as follows: Section 2 provides an overview of the 
possible avenues for forecasting spare parts demand. Section 3 covers the literature selection process. Section 4 constitutes the main part of the paper, discussing the main findings from our literature review. We provide details on the use of installed base information for spare part demand forecasting, as well as its value and associated limitations. Section 5 discusses the collection and organization of installed base information and Section 6 provides some concluding remarks.

\section{Background}

\subsection{Spare part characteristics}

Maintenance parts have specific properties that make them different from many products. We refer to Huiskonen (2001); Kennedy et al. (2002); Boylan \& Syntetos (2010); Bacchetti \& Saccani (2012) for a detailed review of service parts characteristics. The most prominent part characteristics, and especially those related to difficulties in forecasting, are (1) part demands exhibit patterns that are difficult to predict, (2) they are generated by maintenance policies and part breakdowns, and (3) they are subject to obsolescence.

A first distinctive characteristic of spare parts is their demand pattern, which is quite different from the demand pattern of many other products. Even though some spare parts have a high and/or stable demand, the great majority face intermittent demand: it is often characterized by sequences of zero demands interspersed by occasional non-zero demands. Moreover, the demand size itself may be highly variable, in which case it is called erratic. When a demand pattern is both intermittent and erratic, it is said to be lumpy (e.g., Huiskonen, 2001; Boylan \& Syntetos, 2010; Rego \& Mesquita, 2011). Because of this intermittence and the (sometimes extreme) levels of lumpiness, resulting in a very skewed demand size distribution, the lead time demand cannot always be represented by the normal distribution (Boylan et al., 2008), which is often assumed in standard inventory models. Moreover, because of the limited number of non-zero historical demands it can be hard to estimate the distribution of the lead time demand (Hua et al., 2007). The intermittent demand pattern renders demand forecasting a challenging exercise, as standard forecasting techniques oftenproduce inaccurate results. Therefore, specific forecasting techniques have been developed for intermittent spare part demand.

Second, spare parts differ from work-in-process or final products. Unlike end products, that have independent demand and tend to be fast moving, or parts whose demand is dependent on the product demand via the Bill-of-Materials, a spare part is required when the corresponding installed part fails or is replaced preventively (Fortuin \& Martin, 1999). The consumption of spare parts is thus closely related to maintenance. The purpose of spare parts inventories is then to assist maintenance staff in keeping the equipment in operating condition. Maintenance policies and breakdowns, rather than customer usage, dictate the need for spare parts inventories (Kennedy et al., 2002; Gu et al., 2015).

Thirdly, along with the life cycle of products the part specificity generates a risk of obsolescence (e.g., Cohen et al., 2006; Boone et al., 2008; Rego \& Mesquita, 2011). Because most spare parts have specialized uses, they remain in inventory until their installed equipment require it (Kennedy et al., 2002). When the products for which the parts were designed are discontinued, clients can still use the product and generate demand for spare parts when asking for a repair. Heavy equipment may continue to generate a demand for spare parts 
even decades after the end of production (Boone et al., 2008). However, because the installed machines will be taken out of operation over time and no new machines are sold anymore, the risk of obsolescence for the parts increases (Kennedy et al., 2002; Teunter et al., 2011). Incorporating this obsolescence into forecasting techniques may therefore reduce the risk of unneeded stocks.

\subsection{Forecasting methods for spare part demand}

A seminal work for forecasting intermittent demand was written by Croston (1972). Instead of focusing on the mean demand per period, he divided demand into two separate components: demand size and demand occurrence. He then made two separate estimates; one of the inter-demand interval and one of the size of the demand when it occurs. Croston's method (CR) has been adjusted and revised by many authors: Schultz (1987), Johnston \& Boylan (1996), Syntetos (2001), Syntetos \& Boylan (2001) and Syntetos \& Boylan (2005) (SBA), Snyder (2002), Levén \& Segerstedt (2004), Teunter et al. (2011) (TSB), and very recently by Pennings et al. (2017).

Next to the research stream following Croston (1972), other approaches for intermittent demand/spare part demand forecasting have been developed in literature. Bootstrapping (e.g., Willemain et al., 2004) is a non-parametric approach that permits to forecast the distribution of demand directly, rendering distributional assumptions redundant. Likewise, neural networks (e.g., Kourentzes (2013)) could provide a (non-parametric) tool to forecast intermittent demand, as they allow to capture the interaction between non-zero demand and inter-arrival rate of demands. Judgmental forecasting (e.g., Wang \& Petropoulos, 2016) is oftentimes used to adjust quantitatively derived forecasts, and can result in improved forecast accuracy (Syntetos et al., 2009b). Nonetheless, the managerial time requirement renders the method hardly applicable in a practical setting when dealing with thousands of spare parts.

Except for judgmental forecasting, all of the above discussed methods have one major drawback: They only consider historical demand and only react to what happened in the past, i.e., they are forecasting in a reactive way. However, demand might depend on many other factors, and relying only on past consumption might not be accurate (Gu et al., 2015, Beutel \& Minner, 2012). Characterizing the factors that generate demand allows to forecast in a more proactive way (Wang \& Syntetos, 2011), as this anticipates the future demand.

In this paper we review the literature on explanatory forecasting techniques that explicitly consider the drivers of the spare part demand; i.e., the installed base of machines that require a part replacement.

\section{Literature selection and analysis}

We performed a database search looking for articles concerning the use of installed base information for spare part demand forecasting. The (final) search was carried out in June 2018. We analyzed the databases of Emerald Insight, Scopus, JSTOR and Web of Science and used the keywords "spare part" or "service", in combination with "forecast" or "predict", and "installed base". We have excluded work not written in English, and papers which only appeared in conference proceedings. We studied the resulting publications and considered their relevance to the topic under study. For each paper and book chapter, we first evaluated 


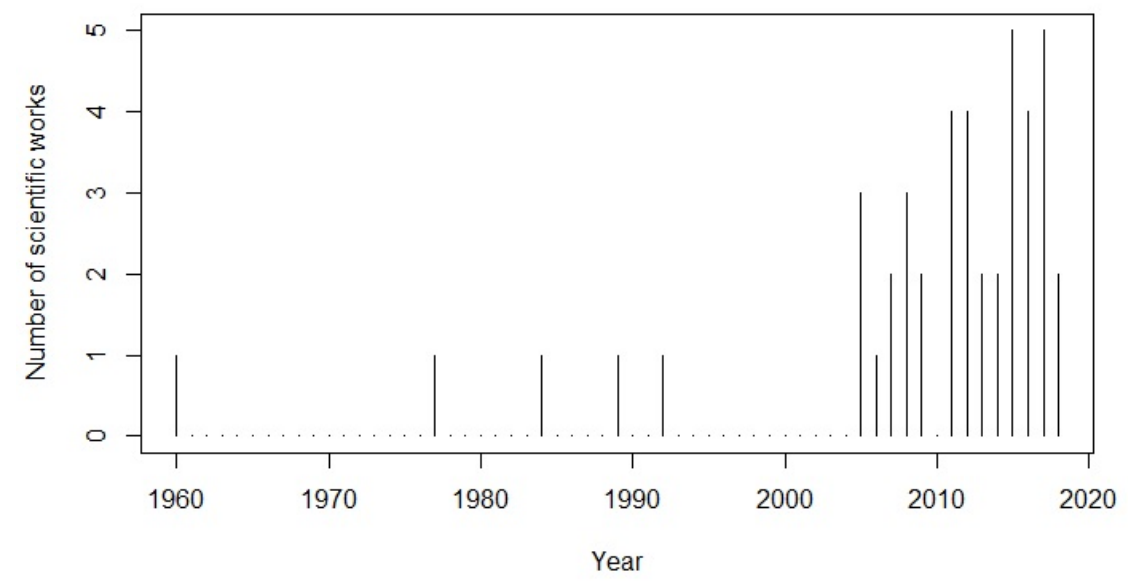

Figure 1: Evolution of the number of published works over time

the title. If this seemed relevant, we considered the abstract, and following the introduction and conclusion. If the paper was still considered relevant, the full paper was analyzed. This initial database search resulted in 11 relevant publications. To extend this number, we complemented our research with two iterations of forward and backward search for the selected papers, evaluating the appropriateness of the cited and citing articles on the topic.

This search resulted in 39 relevant papers and 5 book chapters, presented in Table 1 . All work is published between 1960 and 2018, as graphically presented in Figure 1. The papers are published in 26 different journals and the book chapters stem from five different books, presented in Table 2, in various research fields. We evaluated the relevance of the resulting scientific works in greater detail with regard to our research objectives: (1) What type of installed base information is relevant for forecasting purposes (size of the installed base, maintenance policy in use, failure behavior, etc.); (2) how this information can be used to produce forecasts; (3) what is the value of using installed base information to improve forecasting; and (4) what are the limits of the currently existing methods.

We identified different strands of literature during our review. First, the majority of papers focus on corrective maintenance, and how to use reliability analysis to forecast future spare part demand. A second strand of literature considers preventive and/or condition based maintenance information to enhance demand forecasting. Third, a rather separate series of scientific works focuses on the inclusion of environmental factors that affect the part reliability in the spare part demand forecasts. In addition, there are a number of scientific works that discuss miscellaneous aspects related to the use of installed base information for spare part demand forecasting. Table 3 presents the papers according to their focus: corrective maintenance, preventive maintenance, focusing on environmental factors, or representing a more general point of view. 


\begin{tabular}{|c|c|}
\hline $\begin{array}{l}\text { Type of scien- } \\
\text { tific work }\end{array}$ & Reference \\
\hline Book (chapter) & 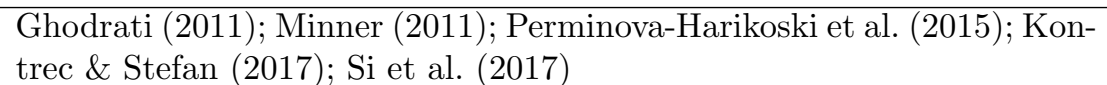 \\
\hline $\begin{array}{l}\text { Paper in peer- } \\
\text { reviewed journal }\end{array}$ & 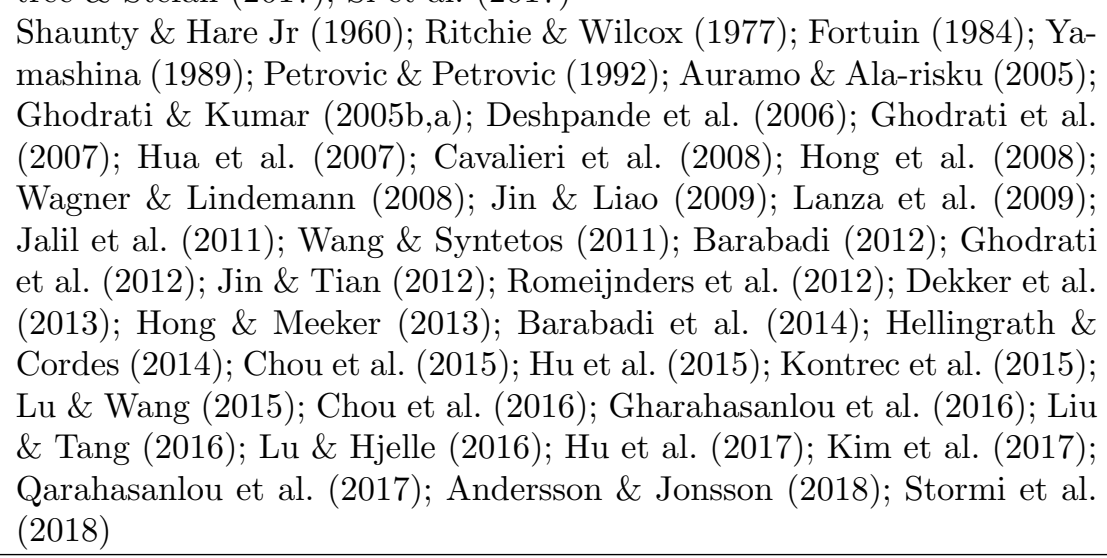 \\
\hline
\end{tabular}

Table 1: Classification of the selected scientific works according to type

\section{Literature review findings}

In this section we discuss the main findings and research directions that result from our literature review. We first provide an overview of the different sources of installed based information (Section 4.1). We then describe the different methods how the installed based information can be used for spare part demand forecasting (Section 4.2). Next, we summarize and discuss the reviewed papers (Section 4.3). And finally, we provide directions for future research (Section 4.4)

\subsection{Definition of installed base information}

The literature review shows that installed base information consists of three main sources of information, that drive spare part demand: (1) the status of the equipment in use and the status of the spare part itself; (2) the maintenance policy that depicts when a part is replaced; and (3) environmental factors that impact the part reliability. These issues are now discussed in more detail.

First, according to Yamashina (1989), three main factors are related to service parts demand: the manufacturing rate of the product, the product life characteristics, and the part life characteristics. Similarly, Minner (2011) and Auramo \& Ala-risku (2005) refer to the age and status of products and systems in use as a source of information. Hong et al. (2008) add the replacement probability of the failed part, because a failed part is not necessarily replaced, or it might be replaced by an unauthorized part as well. Dekker et al. (2013) and Kim et al. (2017) argue that the demand for spare parts follows the demand for the installed product with a delay. It is thus dependent on the product life-cycle. The product life cycle and the impact on spare parts demand is illustrated in Figure 2. In the initial phase where product sales ramp up and the installed base grows, the demand for spare parts is usually rather low, as products are still relatively young. In the mature phase, where product sales gradually fall back and the installed base is at its maximum size, the 


\section{Journal}

CIRP Annals - Manufacturing Technology 1

Computers and Industrial Engineering $\quad 2$

Engineering Costs and Production Economics 1

European Journal of Operational Research 5

IIE Transactions 2

International Journal of Industrial engineering $\quad 1$

International Journal of Information and Management Sciences 1

International Journal of Logistics: Research and Applications 2

International Journal of Mining and Geo-Engineering $\quad 1$

International Journal of Mining, Reclamation and Environment $\quad 1$

International Journal of Performability Engineering $\quad 1$

International Journal of Physical Distribution and Logistics Management 1

International Journal of Production Economics 2

International Journal of Quality and Reliability Management 1

International Journal of Simulation Modeling 2

Journal of Quality in Maintenance Engineering 2

Journal of Service Management $\quad 1$

Journal of the Operational Research Society 2

Management Technology 1

Mathematical Problems in Engineering 2

Operations Research 1

Production and Manufacturing Research 1

Production Planning and Control 2

Reliability Engineering and Systems Safety 1

Technometrics 1

Transportation Research Part E 1

\section{Book}

Data-Driven Remaining Useful Life Prognosis Techniques 1

Replacement Models with Minimal Repair $\quad 1$

Service Parts Management $\quad 1$

Strategic Change towards Future Industrial Service Business 1

System Reliability 1

Table 2: Classification of the papers according to the different journals 


\begin{tabular}{|c|c|}
\hline Strand of literature & Papers \\
\hline Corrective maintenance & 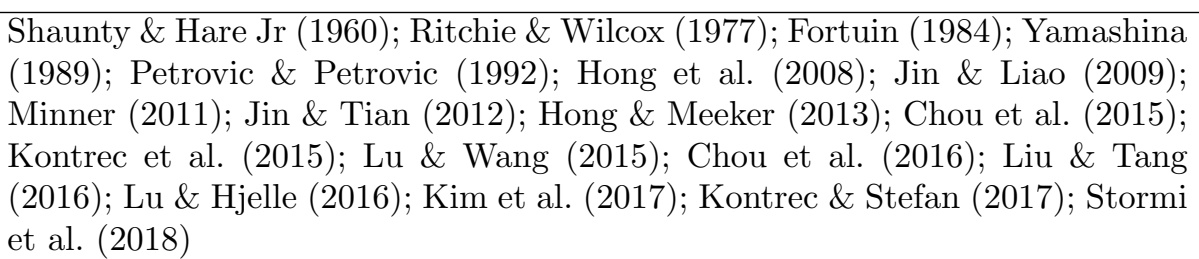 \\
\hline Preventive Maintenance & $\begin{array}{l}\text { Deshpande et al. }(2006) ; \text { Hua et al. }(2007) ; \\
\text { jnders et al. }(2012) ; \text { Wang \& Syntetos (2011); } \text {; Romei- } \\
(2017)\end{array}$ \\
\hline Environmental factors & 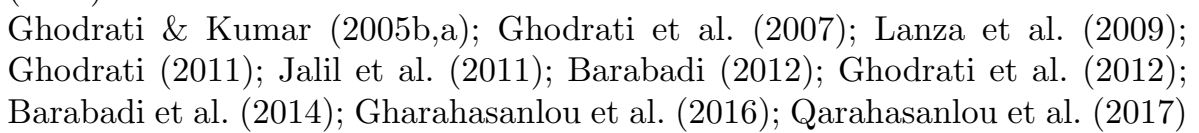 \\
\hline Miscellaneous & $\begin{array}{l}\text { Auramo \& Ala-risku }(2005) ; \text { Cavalieri et al. }(2008) ; \text { Wagner \& Lindemann } \\
\text { (2008); Dekker et al.|(2013); Perminova-Harikoski et al. (2015); Hu et al. (2017); } \\
\text { Andersson \& Jonsson (2018) }\end{array}$ \\
\hline
\end{tabular}

Table 3: Classification of the scientific work according to the research focus

spare part demand is expected to rise. In the end-of-life (EOL) phase, where product sales end, the demand for spare parts can still continue to increase, before it gradually diminishes as more products reach their end-of-use (Kim et al., 2017). From this figure it can be seen that the demand for spare parts follows the demand for the product, albeit with a delay.

Second, the maintenance policy can be considered as a driver of spare parts demand. Wang \& Syntetos (2011) argue that failure-based spare parts management is very different from preventive-maintenance spare parts management, as demand in the former case originates from part failures and in the latter from preventive maintenance actions. Whereas corrective maintenance is characterized by stochastic arrivals of demand, but also by a deterministic demand size (often one unit), preventive maintenance has a deterministic demand arrival, as it is known in advance, but it may have a stochastic demand size as a part is not always replaced after inspection. This distinction is illustrated in Figure 3. Dekker et al. (2013) and Poppe et al. (2017) note that maintenance information is especially important when predicting parts demand for planned maintenance, as those generate advance demand information. In practice, however, it often happens that if some demands for spare parts are planned, while others are unplanned, they are all treated as being the same, i.e., unpredictable without taking into account the maintenance policy.

Third, Ghodrati \& Kumar (2005a b) additionally identify the operating environment in which the installed base operates (e.g., the humidity or the dust) as a factor that affects part reliability and as such spare part demand. Similarly, Jalil et al. (2011) and Andersson \& Jonsson (2018) use information on the regional distribution of the installed products (e.g., the installed base may be concentrated in certain regions).

Once the set of installed base information is defined, the question arises how to obtain this installed base information. Based on interviews with five companies, Auramo \& Ala-risku (2005) recognize the importance of managing installed base information for the purpose of improving the management of industrial services, but at the same time they remark that having reliable information available on all the relevant products in the installed base can 


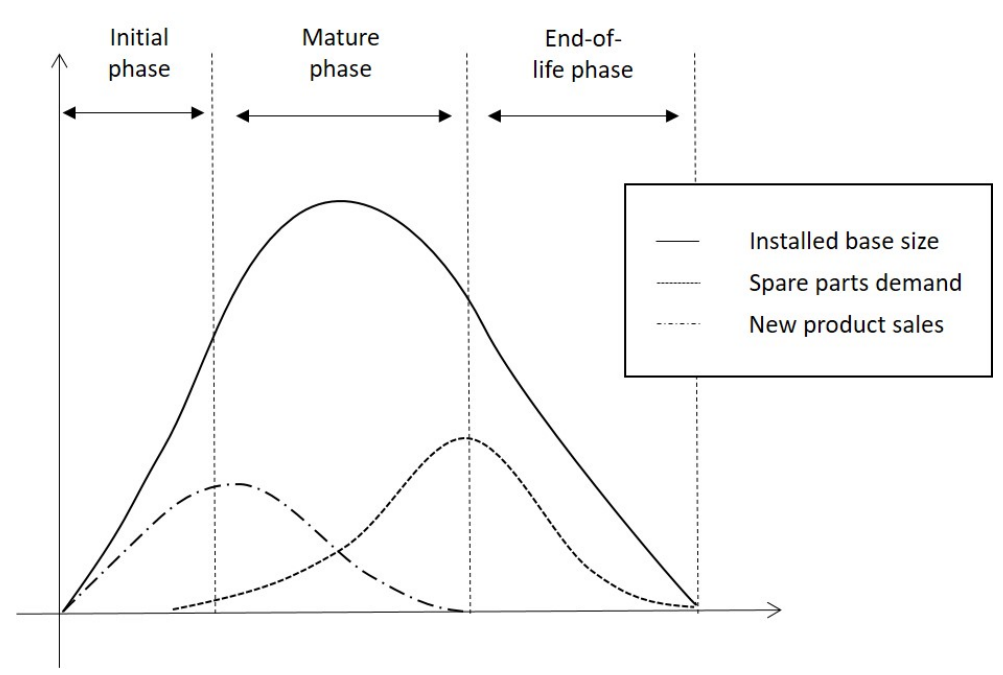

Figure 2: Product life cycle, installed base evolution, and spare parts demand (adapted from Dekker et al. (2013)).

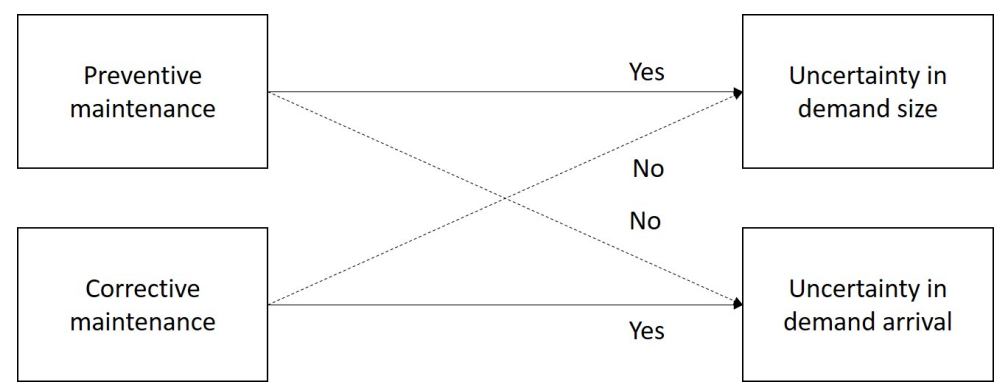

Figure 3: Corrective versus preventive maintenance

be very challenging. Similar insights are obtained by Wagner \& Lindemann $(2008)$, who found in a case study with seven engineering companies that most of the companies only have a 'cloudy view' of their installed base, and specific information, or even the exact number of products sold, are difficult to determine. As the installed base can consist of complex equipment with different subassemblies and parts, it is necessary to keep track of the complete composition and potential technical improvements and maintenance actions in order to keep track of the installed base (Dekker et al., 2013). Moreover, companies generally do not have information on where/how the customer uses the product. As such, they could base their forecasts on some wrong installed base information. To resolve this issue, Perminova-Harikoski et al. (2015) claim customer interactions as an important source of installed base data and an opportunity for data collection. Along the same lines, Kim et al. (2017) identify maintenance contracts as an important source of installed base information.

\subsection{Methods to use installed base information for spare part demand forecasting}

In a very early attempt, Shaunty \& Hare Jr (1960) link spare parts demand to product usage. They investigate this connection in the specific setting of aircraft spare parts, whose demand is estimated based on the number of landings of the planes. Therefore, they estimate 
the failure rate of a part per 'usage', here defined as the number of landings, and multiply it with the scheduled number of landings at a certain location per time period (e.g., per week) for a certain plane type. When these part needs are summed over all planes planned to land at a given station, the forecasted need for that location is obtained.

Rather than assuming a constant installed base, several authors acknowledge the evolution of the installed base over time. As illustrated in Figure 2, the number of installs increases during the initial phase of the product life cycle, reaches a maximum level within the mature phase, and decreases during the end-of-life phase (Inderfurth \& Mukherjee, 2008).

Jin \& Liao (2009) claim that neglecting the increase in product installations, due to market expansion, underestimates the actual maintenance needs. This is later confirmed by|Jin \& Tian (2012) using simulation studies. Fortuin (1984) investigates this for the introduction of a new product, where an initial forecast for the future spare part demand is made using a rough estimate for the part failure rate and a linear increase of product demand.

Ritchie \& Wilcox (1977), Hong et al. (2008), Chou et al. (2015, 2016), and Kim et al. (2017) treat the case of a discontinued product, where no new sales occur in the future and installed products can be discarded due to end of use. This often occurs in practice, as the service period of a product is typically much longer than the production period (Teunter \& Fortuin, 1999). In that case the installed base is decreasing over time. Chou et al. (2015, 2016) highlight the importance of including the decline in installed base, as the part production costs during the EOL phase might be much larger than in the mature phase because of limited economies of scale and scope, and overstocking is very costly as unsold parts will become obsolete. Ritchie \& Wilcox (1977) introduce the probability that a part, when it fails, is not replaced. They argue that the decrease in spare parts demand originates from the non-replacement decision for defective parts in old machines, rather than from the decay in the number of installed machines over time. Hong et al. (2008) extend the work of Ritchie \& Wilcox (1977), by combining a decline in installed base with a replacement probability. Instead of using a reliability model, Chou et al. $(2015,2016)$ find that regression on the failure probability leads to more accurate forecasts than regression on historical part sales data. Kim et al. (2017) also present a regression methodology, to make an accurate last make/buy decision. Noteworthy, the authors study spare part demand for consumer products, such as refrigerators and televisions, whereas most other works study capital goods, like planes or heavy equipment.

The part replacement probability is also discussed by Lu \& Wang (2015), who assume that the repair willingness of a customer decreases with the cumulative number of breakdowns the product as a whole has experienced in the past. Lu \& Hjelle (2016) extend this idea by evaluating whether users will have their product repaired depending on both the number of past failures and the use time.

Yamashina (1989) includes new product installations, which are added to the installed base, together with product survival, where products leave the installed base, over time, and thus addresses the entire product life cycle. He relates service parts demand to the production pattern of products containing the studied part (implicitly assuming that each produced product is also installed), together with the product life characteristics (i.e., when it is discarded), and the part life characteristics (i.e., failure rate). The author however remarks the difficulty of calculating the demand forecast analytically when the future product sales are a stochastic process. Minner $(\overline{2011})$ models the evolution of the installed base by 
the new product sales and the end-of-use of products. The author determines the probability distribution, instead of a point forecast, for the one-period-ahead demand by means of recursion.

Kontrec et al. (2015) and Kontrec \& Stefan (2017) propose a reliability model where they observe the total unit time, i.e., the average life span of a part, and use it to estimate the number of parts to be kept in stock. Stormi et al. (2018) propose a regression model which only considers the size of the installed base as the driver for demand, and ignore the failure behavior of the parts. Nonetheless, the authors observe the existence of a replacement probability when applying their method in a case study. In the research of Hong \& Meeker (2013) the failure occurrence is considered to be dependent on the dynamic use rate of the product, and not on calendar time.

The method of Liu \& Tang (2016) differs from all previous research as it assumes that sub-failure processes of items on the same system are not necessarily independent. The authors also include the possibility of reliability improvement or deterioration over time.

Several papers discuss the impact of environmental factors on the part reliability distribution. The environmental operating conditions, such as the temperature, humidity, dust, etc., can have an influence on the reliability characteristics of the product. Ghodrati \& Ku$\operatorname{mar}(2005 \mathrm{a}, \mathrm{b})$; Ghodrati (2011) propose a method to obtain the expected number of spare parts using system reliability and environmental data. They adjust a baseline part failure rate with time-independent covariates that are associated with environmental factors to account for different operating conditions. Using an Event tree analysis, Ghodrati et al. (2007) find that ignoring the operating environment results in economical and production losses. Their method and findings are implemented and validated at a case company in Ghodrati et al. (2012) and Barabadi et al. (2014). In the work of Lanza et al. (2009) and Barabadi (2012) the parameters of the part reliability function are adjusted based on time-dependent covariates. Using a case study, Gharahasanlou et al. (2016) and Qarahasanlou et al. (2017) validate the importance of including (time-dependent) covariates related to the operating conditions in the spare part demand forecasts.

A different installed base approach is used by Jalil et al. (2011), who study where to place the spare part inventories throughout a service network. They make an aggregate forecast for an entire region, where they sum up the historical spare part demand observed at each location. Next, an extrapolation method is used (e.g., Simple Exponential Smoothing (SES)) to derive a demand forecast for the entire region. Information on the size of the current installed base is then used to allocate and divide the aggregated forecast geographically.

Finally, in addition to the spare part requirements for corrective (or reactive) maintenance, several authors analyze the spare part demand originating from preventive (or proactive) maintenance. Ghobbar \& Friend (2002, 2003) discuss three primary (preventive) maintenance processes: hard-time (periodic maintenance), on-condition (periodic inspections), and condition monitoring. The first two involve periodic maintenance visits related with preventing failures, whereas the third only leads to a preventive maintenance visit based on the condition of the part. The classification of the studied papers considering preventive maintenance can be found in Table 4 .

Hua et al. (2007) develop a regression model in which they attribute nonzero demand to 
Maintenance Process

Periodic maintenance (Hard-time)

Periodic Inspections (On-condition)

Condition-monitoring

\section{Papers}

Hu et al. $(2015)$

Hua et al. (2007); Wang \& Syntetos (2011); Romeijnders et al. (2012)

Deshpande et al. (2006); Hellingrath \& Cordes (2014); Si et al. (2017)

Table 4: Classification of the scientific work considering preventive maintenance

the occurrence of planned maintenance actions. Hu et al. (2015) consider a two-dimensional preventive maintenance cycle, where preventive replacement scheduling is dependent on both calendar time and usage time (e.g., mileage, flight hours, etc.), to forecast future demand. Romeijnders et al. (2012) propose a two-step forecasting method, in which they separately forecast the number of repairs for each type of component and the average number of parts of the studied type needed per repair of that component.

Wang \& Syntetos (2011) look at a case of preventive maintenance where items are inspected at regular intervals and can be replaced if defective and consider a delay time based model to forecast future spare parts demand. Si et al. (2017) build on the idea of Wang \& Syntetos (2011) to use real-time condition-monitoring degradation data of the system instead of statistical failure data to produce their forecasts. Condition monitoring data are also used by Hellingrath \& Cordes (2014) to enhance the demand forecast quality: in a first step, condition monitoring information is analyzed with regard to distribution parameters of potential breakdowns, which is then in a second step combined with a Bayesian approach (Dolgui \& Pashkevich, 2008) to provide a probability distribution for the future spare parts demand.

Finally, Deshpande et al. (2006) apply a somewhat different approach using condition monitoring data to improve the predictability of service parts demand: they develop a condition based advance order policy, where each installed part with an age higher than a certain threshold generates advance demand information and triggers an advance order. The use of these advance orders improves the availability of the spare parts.

\subsection{Analysis of the reviewed literature}

In what follows we classify the different papers, including an overview of the assumptions made on the future development of the installed base size and the part failure behavior, a review of its evaluation methods, and its most important contributions and limitations.

Table 5 classifies the causal based forecast methods that make use of installed base information into three categories (as in Andersson \& Jonsson (2018)): reliability based forecasting, regression based forecasting, and forecasting using sensor data. The method of Jalil et al. (2011) is not included in this overview, as it uses the installed base information merely as an allocation method, nor is the work of Romeijnders et al. (2012), who apply a time series based forecasting, rather than a causal method. We observe the majority of proposed methods apply reliability based forecasting. In Table 6 we give an overview of the diverse types of information considered by the different methods. Whereas regression based forecasting requires data on explanatory factors that correlate with demand (e.g., the size of the installed base, the part failure behavior, historical failures), forecasting using sensor 


\begin{tabular}{|c|c|}
\hline Category & Papers \\
\hline Reliability based & 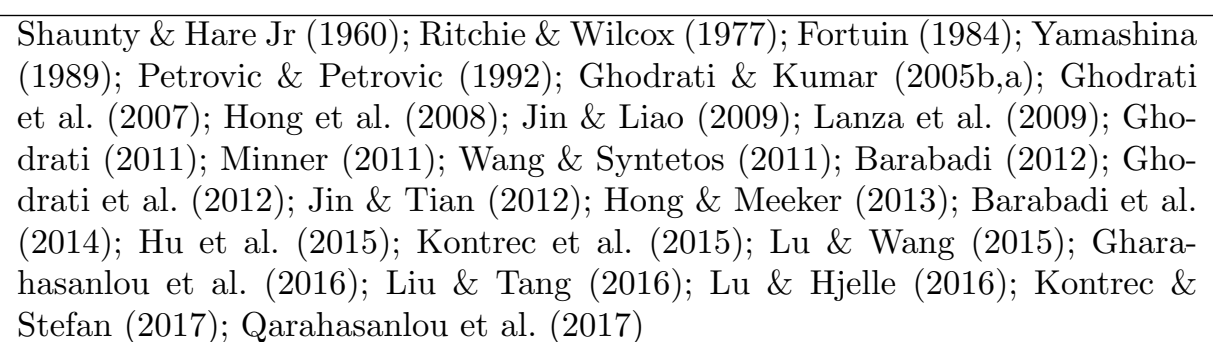 \\
\hline Regression based & $\begin{array}{l}\text { Hua et al. (2007); Chou et al. (2015, 2016); Kim et al. (2017); Stormi et al. } \\
(2018)\end{array}$ \\
\hline Using sensor data & Deshpande et al. (2006); Hellingrath \& Cordes $(2014) ;$ Si et al. $(2017)$ \\
\hline
\end{tabular}

Table 5: Classification of the forecast methods according to Andersson \& Jonsson (2018)

data necessitates sensor data to be collected and analyzed. Reliability based forecasting in turn may use a variety of data: the part failure behavior, the current and future size of the installed base, the geographical location, the usage (conditions) of the installed base, the repair willingness of the customers, and the maintenance policy in place.

Tables 7 and 8 provide an overview of the different assumptions on the future development of the installed base, as also discussed in Section 4.2. We observe that almost all works consider historical product sales and historical discards, without anticipating potential future changes over time. Only six of the 37 works considers an increase in installed base over time through new product sales, and seven consider the decline because of product discards, of which two take both new sales and product discards into account. Only the latter two consider the entire product life cycle of the installed base, where the number of installs increases in the initial phase, reaches a maximum in the mature phase, and declines when the product enters the end-of-life (EOL) phase. Nonetheless, linking the product life cycle with part demand can be beneficial, as time series based methods lag behind the life cycle development (Minner, 2011). In the beginning of the life cycle, explanatory variables related to the installed base can be incorporated to anticipate the future increase in demand, and in the EOL phase, spare part stock should only be kept for items that are still operational (i.e., the active installed base), to reduce or even eliminate obsolete stock (Wagner \& Lindemann, 2008). Especially when product life cycles are long, tracking the installed base may result in inventory reductions (Minner, 2011).

Tables 6 and 9 illustrate the different approaches to the part failure process. Some authors only use the observed historical failures, for example as a dependent variable in a regression analysis, but do not model the part failure behavior itself. Those are indicated with $(\mathrm{H})$ in Table 6. Table 9 shows that the Exponential and Weibull distribution are commonly used to model the part failure process; Where the use of an Exponential time-to-failure distribution, or a constant failure rate, facilitates calculations, it is a simplifying assumption which does not necessarily hold in practice. The Weibull distribution, on the contrary, might be more appropriate in a practical setting, although more complex to apply (Ghodrati, 2011).

In Table 6 we observe that environmental factors are included in eleven out of 37 works. It is remarkable that none of the studied papers considers environmental factors together with 
an evolving installed base size. Most papers include the impact of the environment (such as humidity, dust, temperature, etc.) on the part reliability through covariates. A different approach is applied by Jalil et al. (2011), who use the environment (the geographical location of the installed base) as an allocation method for their time series based forecast.

Table 10 indicates the assumptions taken on the part replacement probability. Only six out of 37 works consider a replacement probability.

Table 11 summarizes how the different authors validate and/or evaluate their forecast methods, if applicable, together with the main results. We observe that most methods show promising performance, either in terms of increased forecast accuracy and/or reduced inventories. Nonetheless, it is remarkable that some authors do not include any means of forecast evaluation nor validation in their work, e.g., Shaunty \& Hare Jr (1960); Yamashina (1989); Petrovic \& Petrovic (1992); Lanza et al. (2009). These papers are excluded from Table 11. Moreover, some authors apply their method to a real dataset, but without validation to the actual demand (e.g., Ghodrati \& Kumar, 2005a. b; Kontrec et al., 2015), or evaluation relative to other methods (e.g., Ritchie \& Wilcox, 1977; Jin \& Liao, 2009; Lu \& Wang, 2015). And in those cases were the methods are evaluated, we find that very different measures (e.g., inventory costs, Mean Absolute Deviation (MAD), Mean Squared Error (MSE), Mean Absolute Percentage Error (MAPE)) and benchmark methods (e.g., current company policy, SBA, CR, SES, bootstrapping) are applied. We also observe a lack of overall comparison among the various installed base methods. That renders it hard to evaluate the performance across the different methods. An exception to this is Hong et al. (2008), who explicitly compare their method performance with the method by Ritchie \& Wilcox (1977). Ghodrati (2011) also investigates the impact of using an exponential time-to-failure distribution (Ghodrati \& Kumar, 2005a) versus a Weibull distribution (Ghodrati \& Kumar, 2005b) when including covariates.

In Tables 12 and 13 , we finally present an overview of the main contributions and limitations to the discussed scientific works. From Table 12 we clearly observe a trend towards more complexity of the proposed methods over time, through an increased amount of installed base information that is considered. This reflects a closer match between the developed methods and reality. Table 13 shows that for many papers, the main challenge lies in the proper estimation of the method parameters (part replacement probability, impact of environmental factors, evolution of the installed base, etc.). The proposed methods can only perform well if this data is available and reliable. Generally, the authors assume availability and observability of the necessary data. In practice, however, this is quite a strong assumption. To overcome difficulties with parameter estimations and limited failure data availability, Petrovic \& Petrovic (1992) apply theoretical failure rates estimated from data banks or reliability handbooks in their forecast. Cavalieri et al. (2008) recommend predicting the failure rate using past failures or reliability testing. Nonetheless, they acknowledge that this requires the history of failures to be registered in a database (which is also addressed by Andersson \& Jonsson (2018)). When data is missing, Lanza et al. (2009) suggest to base reliability parameters on expert knowledge. 


\begin{tabular}{|c|c|c|c|c|c|c|c|}
\hline Paper & $\begin{array}{l}\text { Historical } \\
\text { sales }\end{array}$ & $\begin{array}{l}\text { New } \\
\text { sales }\end{array}$ & $\begin{array}{l}\text { Historical } \\
\text { discards }\end{array}$ & $\begin{array}{l}\text { Future } \\
\text { discards }\end{array}$ & Failures & $\begin{array}{l}\text { Replacement } \\
\text { probability }\end{array}$ & Environment \\
\hline Shaunty \& Hare Jr $(1960)$ & $\mathrm{x}$ & & $\mathrm{x}$ & & $\mathrm{x}$ & & \\
\hline Ritchie \& Wilcox (1977) & $\mathrm{x}$ & & & & $\mathrm{x}$ & $\mathrm{x}$ & \\
\hline Yamashina $(1989)$ & & $\mathrm{x}$ & & $\mathrm{x}$ & $\mathrm{x}$ & & \\
\hline Petrovic \& Petrovic & $\mathrm{x}$ & & $\mathrm{x}$ & & $\mathrm{x}$ & & \\
\hline Ghodrati \& Kumar $(2005 \mathrm{~b}, \mathrm{a})$; Ghodrati et al. & $\mathrm{x}$ & & $\mathrm{x}$ & & $\mathrm{x}$ & & $\mathrm{x}$ \\
\hline (2007); Ghodrati (2011); Ghodrati et al. (2012) & & & & & & & \\
\hline Hong et al. $(2008)$ & $\mathrm{x}$ & & & $\mathrm{x}$ & $\mathrm{x}$ & $\mathrm{x}$ & \\
\hline Jin \& Liao (2009; ; Jin \& Tian $(2012)$ & & $\mathrm{x}$ & & & $\mathrm{x}$ & & \\
\hline Lanza et al. $[2009]$ & $\mathrm{x}$ & & $\mathrm{x}$ & & $\mathrm{x}$ & & $\mathrm{x}$ \\
\hline Jalil et al. (2011) & $\mathrm{x}$ & & $\mathrm{x}$ & & $(\mathrm{H})$ & & $\mathrm{x}$ \\
\hline Minner (2011) & & $\mathrm{x}$ & & $\mathrm{x}$ & $\mathrm{x}$ & & \\
\hline Wang \& Syntetos $(2011)$ & $\mathrm{x}$ & & $\mathrm{x}$ & & $\mathrm{x}$ & & \\
\hline Barabadi (2012) & & & & & $\mathrm{x}$ & & $\mathrm{x}$ \\
\hline Chou et al. (2015) & $\mathrm{x}$ & & $\mathrm{x}$ & $\mathrm{x}$ & $\mathrm{x}$ & $\mathrm{x}$ & \\
\hline Hu et al. $(2015$ & $\mathrm{x}$ & & $\mathrm{x}$ & & $\mathrm{x}$ & & \\
\hline Kontrec et al. (2015) & $\mathrm{x}$ & & $\mathrm{x}$ & & $\mathrm{x}$ & & \\
\hline Lu \& Wang 2015 & $\mathrm{x}$ & & $\mathrm{x}$ & & $\mathrm{x}$ & $\mathrm{x}$ & \\
\hline Gharahasanlou et al. (2016) & $\mathrm{x}$ & & $\mathrm{x}$ & & $\mathrm{x}$ & & $\mathrm{x}$ \\
\hline Chou et al. (2016) & $\mathrm{x}$ & & $\mathrm{x}$ & $\mathrm{x}$ & $\mathrm{x}$ & $\mathrm{x}$ & \\
\hline Liu \& Tang 2016 & $\mathrm{x}$ & $\mathrm{x}$ & & & $\mathrm{x}$ & & \\
\hline Lu \& Hjelle & $\mathrm{x}$ & & $\mathrm{x}$ & & $\mathrm{x}$ & $\mathrm{x}$ & \\
\hline Kim et al. $(2017)$ & $\mathrm{x}$ & & $\mathrm{x}$ & $\mathrm{x}$ & $\mathrm{x}$ & & \\
\hline Kontrec \& Stefan 2017 & $\mathrm{x}$ & & $\mathrm{x}$ & & $\mathrm{x}$ & & \\
\hline Qarahasanlou et al. $(2017)$ & $\mathrm{x}$ & & $\mathrm{x}$ & & $\mathrm{x}$ & & $\mathrm{x}$ \\
\hline \begin{tabular}{|l|l|} 
Si et al. $(2017$ \\
\end{tabular} & & & & & $\mathrm{x}$ & & \\
\hline Stormi et al. $(2018)$ & $\mathrm{x}$ & & $\mathrm{x}$ & $\mathrm{x}$ & $(\mathrm{H})$ & & \\
\hline
\end{tabular}

Table 6: Sources of installed base information 


\begin{tabular}{ll} 
Paper & New sales \\
\hline Fortuin $(\overline{1984})$ & Linear growth function \\
\hline Yamashina $(1989)$ & Time dependent sales rate / Lump production \\
\hline Jin \& Liao $(\overline{2009})$ & Homogeneous Poisson Process \\
\hline Minner $(2011)$ & Logistic growth function \\
\hline Jin \& Tian $(2012)$ & Homogeneous Poisson Process \\
\hline Liu \& Tang & Deterministic \\
\hline
\end{tabular}

Table 7: Assumptions on the distribution of the new sales

\begin{tabular}{|c|c|}
\hline Paper & Product Discards \\
\hline Yamashina $(1989)$ & Not specified \\
\hline Hong et al. $(2008)$ & Exponential survival function \\
\hline Minner $(2011)$ & Sum of Binomial distributions \\
\hline Chou et al. (2015) & Integrated in the expression of the replacement probability \\
\hline Chou et al. $(\overline{2016})$ & Integrated in the expression of the replacement probability \\
\hline Kim et al. (2017) & Exponential survival function \\
\hline Stormi et al. (2018) & Exponential survival function \\
\hline
\end{tabular}

Table 8: Assumptions on the distribution of product discards

\subsection{Future research directions}

From Tables 6- 10 it can be concluded that a wide range of assumptions exist on the use of installed base information. Despite the potential value of the installed based forecasting methods, the majority of them are not easy to implement in practice as they rely upon a great number of simplifying assumptions, that cannot necessarily be sustained in practice.

Noteworthy, none of the studied method considers all all relevant demand drivers; most of the work is tailored to a specific PLC phase. This allows to simplify the method, but unfortunately they are not applicable in the other PLC phases. Moreover, we observe that environmental factors are rarely combined with a changing installed base size. Also a part replacement probability is hardly considered. Consequently, an avenue for future research is the development of a method that takes a broader number of drivers into account. It is expected that this will lead to even better performance.

Moreover, we find that a common evaluation measure to compare the different forecasting methods is lacking; currently, many different measures and different benchmark methods are used and there is no comparison between the different installed base methods. We consequently identify a need for a large scale evaluation of the proposed methods, to investigate their relative performance and their performance compared to traditional methods, to formally investigate potential gains and investigate the value of (not) including different demand drivers. For this purpose, it could be interesting to establish a link between classification techniques and the use of installed base information. As regions of superior performance have been drawn up for SES, CR, and SBA (Syntetos \& Boylan, 2005), it might also be interesting to define a region in which the inclusion of installed base information is useful.

Besides, we find that most methods are concerned with the estimation of many parameters, and as such they necessitate data collection and analysis. This might be a challenge 
Paper

Shaunty \& Hare Jr (1960)

Ritchie \& Wilcox (1977)

Fortuin (1984)

Yamashina (1989)

Petrovic \& Petrovic (1992)

Ghodrati \& Kumar (2005b)

Ghodrati \& Kumar (2005a)

Deshpande et al. (2006)

Ghodrati et al. (2007)

Hong et al. (2008)

Jin \& Liao (2009)

Lanza et al. (2009

Ghodrati (2011)

Minner (2011)

Wang \& Syntetos (2011)

Barabadi (2012)

Ghodrati et al. (2012)

Jin \& Tian (2012)

Hong \& Meeker (2013)

Barabadi et al. (2014)

Hellingrath \& Cordes (2014)

Chou et al. (2015)

Hu et al. (2015)

Kontrec et al. (2015)

Lu \& Wang (2015)

Chou et al. (2016)

Gharahasanlou et al. (2016)

Liu \& Tang (2016)

Lu \& Hjelle (2016)

Kim et al. (2017)

Kontrec \& Stefan 2017

Qarahasanlou et al. (2017)

Si et al. (2017)

\section{Failure process}

Constant failure rate

Constant failure rate

Exponential time-to-failure distribution

Exponential time-to-failure distribution

Constant failure rate

Weibull time-to-failure distribution

Exponential time-to-failure distribution

No distribution specified

Exponential time-to-failure distribution

Exponential time-to-failure distribution

Exponential and Weibull time-to-failure distribution

Weibull time-to-failure distribution

Exponential and Weibull time-to-failure distribution

Bernoulli process, probability dependent on part age

Weibull time-to-failure distribution

Weibull time-to-failure distribution

Exponential time-to-failure distribution

Exponential time-to-failure distribution

Weibull time-to-failure distribution

No distribution specified

No distribution specified

No distribution specified

Weibull time-to-failure distribution

Rayleigh time-to-failure distribution

Exponential time-to-failure distribution

No distribution specified

Weibull time-to-failure distribution

Weibull time-to-failure distribution

Exponential time-to-failure distribution

Exponential part survival function

Rayleigh time-to-failure distribution

No distribution specified

Wiener degradation process

Table 9: Assumptions on the failure rate

when implementing the methods in a practical setting. Nonetheless, data management practices are hardly discussed when new methods are proposed, and they assume data to be available and observable. Therefore, a validation of the methods on real data, together with a discussion of the data collection and analysis process, could extend the current knowledge. In addition to that, an evaluation of the impact of imperfect or incomplete information could bring the methods closer to a practical setting.

Lastly, as all methods require a large database to be available, we propose the investigation of the potential to combine installed base information together with more traditional methods, as similarly suggested by Furtak et al. (2015); Hu et al. (2017); Andersson \& Jonsson (2018). Such approaches, as presented by Jalil et al. (2011) and Romeijnders et al. (2012), allow to apply a simple method that requires little (advanced) data and enrich it with installed base information. Installed base information could thus be used to adjust 


\begin{tabular}{|c|c|}
\hline Paper & Replacement probability \\
\hline Ritchie \& Wilcox $\overline{1977)}$ & Exponential replacement probability distribution \\
\hline Hong et al. $(2008)$ & Exponential replacement probability distribution \\
\hline Chou et al. $(\overline{2015})$ & Exponential replacement probability distribution \\
\hline Lu \& Wang (2015) & Probabilities based on survey data, no distribution specified \\
\hline Chou et al. $(2016)$ & Exponential replacement probability distribution \\
\hline 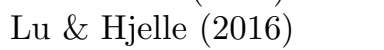 & Probabilities based on survey data, no distribution specified \\
\hline
\end{tabular}

Table 10: Assumptions on the replacement probability

traditional methods, whilst reducing the need for a complex forecasting method.

\section{Collection and organization of installed base information}

Dekker et al. (2013) remark that obtaining the necessary information to produce forecasts using installed base information can be very difficult and time consuming. Using three business cases, they investigate whether it is worth the effort. The authors find that the use of installed base information increases accuracy and timeliness of the forecasts. An issue that remains open, from a practical perspective, is how to make all this information readily available. As stated by Andersson \& Jonsson (2018), explanatory variables need to be identified and analyzed, in order to benefit from installed base forecast methods. Moreover, data needs to be available and of high quality. The IT advances and storage capacities that can permit the collection and analysis of such 'big data' exist. In automobiles, for example, more and more vehicles are linked by telematics, and the amount of data generated by those telematics is increasing (Andersson \& Jonsson, 2018). More and more machines, too, are equipped with sensors that can collect various kinds of data and allow for direct monitoring of the products in use (Furtak et al., 2015; Andersson \& Jonsson, 2018). Zhong et al. (2016) present an overview of recent big data collection and analytics tools, developed by large IT companies, such as SAP, Microsoft, and Oracle. According to the authors, big data has emerged in recent years as a discipline that can provide possible solutions for data analysis, knowledge extraction, and advanced decision making. Through company interviews, the study of Richey et al. (2016) finds that firms see forecasting as one of the primary big data opportunities for the future.

The ultimate goal of collecting and storing big data is to convert it into meaningful information that can be used to improve decision making (Richey et al., 2016). Nonetheless, the usability of the collected information greatly depends on how the data is collected, and the required quality and detail. In some industries, data collection is regulated, dictating which info to collect. In others, however, data availability might be an issue and even basic info might be missing (Perminova-Harikoski et al., 2015). Consequently, companies tend to only have a 'cloudy' view of their installed base (Wagner \& Lindemann, 2008). Moreover, collected data can be heterogeneous, unstructured, or incompatible, which complicates data integration (Zhong et al., 2016). As such, even when companies build large databases, they can fail to accurately analyze the collected data. A possible cause is identified by Mahlamäki et al. (2016), who state that it is difficult to see the value of installed base information before it is utilized. 
As such, more than only a technological development, it is also a matter of a cultural shift for people to start storing this information and, more importantly, attempt to use it for forecasting purposes. Top management does not always clearly understand the future benefits of investing in big data practices. This lack of management support can lead to delayed implementation of big data-generated solutions (Richey et al., 2016). Alghisi et al. (2013) find there exists a relation between the installed base information management practices of equipment manufacturers, such as collecting, analyzing, using, and sharing data, and the level of service orientation of the firm. In many companies, forecasting spare parts demand and the management of inventories and maintenance actions is performed in another department than the one collecting and analyzing operational information (i.e., installed base information). To bring this information together, a close cooperation between departments is required. Inventory controllers and maintenance planners should therefore raise awareness of the importance of installed based information for improving inventory forecasting of spare parts. For this reason, Cavalieri et al. (2008) provide a stepwise decision making path in order to direct a manager on how to handle the management of spare parts in a company. Richey et al. (2016) remark it is important to also hire personnel throughout the firm who are knowledgeable about big data, as they can monitor and improve the data collection process.

\section{Concluding remarks}

A lot of research has already been performed on the topic of forecasting spare parts demand. A large part of this research, however, focuses on extrapolation methods which use historical demand data in order to classify and forecast parts demand. A smaller body of research exists on causal forecasting techniques, which incorporate the real drivers of spare part demand generation. In our literature review we identify 44 relevant papers or book chapters, of which 37 present a method or analysis, and 7 present a literature review or a framework, on the use of installed base information for spare part demand forecasting. Nonetheless, over the past years, interest for the topic has been increasing. When mapping the publications on a time line, we observe that the number increases from 2005 onwards: $70 \%$ has been published in the last 10 years, and $40 \%$ in the past 5 years. In our opinion, this can be explained by the fact that the use of installed base information for forecasting requires a huge amount of data to be available and to be analyzed. These days it is often stated that our most valuable resource is no longer oil, but data (The Economist, 2017). In the past decade, data collection, storage and analytics tools have greatly increased. Also

the field of advanced data analytics is recently growing very fast. As such, we expect the number of papers on this topic to increase more over the coming years.

Establishing a link between the installed machines, the maintenance policy, and spare parts demand seems intuitive, and even self-evident. Therefore we believe that practitioners will appreciate its value. Causal forecasting is also particularly suited for spare parts demand forecasting. This becomes even more important in early stages of the product life cycle, when little historical demand data are available but some information on the installed base might be at hand. In the end-of-life phase, the use of installed base information allows to reduce or even eliminate obsolete stock.

Our literature review motivates the identification of a number of possible future research directions. First of all, it seems intuitive to investigate a method which combines a a broad 
setof demand drivers, such as the preventive maintenance information in combination with the failure rate information, as this captures a large part of the demand generating process. Second, it might be interesting to establish a link between classification techniques and the use of installed base information. As regions of superior performance have been drawn up for SES, CR, and SBA, it might also be interesting to define a region in which the inclusion of installed base information is useful. Therefore, a large scale comparison of different installed base methods with each other and with traditional methods is necessary to formally evaluate their performance, strengths and weaknesses. Third, a profound discussion of data management practices would enrich current literature, as there is a need for information systems that support the data collection and analysis. Fourth, this discussion could be extended by evaluating the impact of imperfect or missing information. Fifth, there is also value in the combination of forecasting techniques. Therefore, a possible research direction could be in further investigating the combination of extrapolation techniques and causal methods.

\section{References}

Alghisi, A., Saccani, N., \& Aggogeri, F. (2013). The Role of Installed Base Information in the Implementation of Service-led Business Models : an Empirical Investigation and a Literature Review. In 20th EurOMA Conference: Operations Management at the Hearth of the Recovery June. Dublin.

Andersson, J., \& Jonsson, P. (2018). Big data in spare parts supply chains: The potential of using product-in-use data in aftermarket demand planning. International Journal of Physical Distribution \& Materials Management, 48, 524-544.

Auramo, J., \& Ala-risku, T. (2005). Challenges for going downstream. International Journal of Logistics: Research and Applications, 8, 333-345. doi:10.1080/13675560500407358.

Babiloni, E., Cardós, M., Albarracin, J., \& Palmer, M. (2010). Demand categorization, Forecasting, and Inventory Control for Intermittent Demand Items. South African Journal of Industrial Engineering, 21, 115-130.

Bacchetti, A., \& Saccani, N. (2012). Spare parts classification and demand forecasting for stock control: Investigating the gap between research and practice. Omega, 40, 722-737. doi:10.1016/j.omega.2011.06.008.

Barabadi, A. (2012). Reliability and spare parts provision considering operational environment: A case study. International Journal of Performability Engineering, 8, 497-506.

Barabadi, A., Barabady, J., \& Markeset, T. (2014). Application of reliability models with covariates in spare part prediction and optimization - A case study. Reliability Engineering and System Safety, 123, 1-7. doi:10.1016/j.ress.2013.09.012.

Beutel, A.-L., \& Minner, S. (2012). Safety stock planning under causal demand forecasting. International Journal of Production Economics, 140, 637-645. doi:10.1016/j.ijpe. 2011.04 .017$. 
Boone, C. A., Craighead, C. W., \& Hanna, J. B. (2008). Critical challenges of inventory management in service parts supply: A Delphi study. Operations Management Research, 1, 31-39. doi:10.1007/s12063-008-0002-2.

Boylan, J. E., \& Syntetos, A. A. (2010). Spare parts management: A review of forecasting research and extensions. IMA Journal of Management Mathematics, 21, 227-237. doi:10. 1093/imaman/dpp016.

Boylan, J. E., Syntetos, A. A., \& Karakostas, G. C. (2008). Classification for Forecasting and Stock Control: A Case Study. Journal of the Operational Research Society, 59, 473-481. doi:10.1086/595006.

Cavalieri, S., Garetti, M., Macchi, M., \& Pinto, R. (2008). A decision-making framework for managing maintenance spare parts. Production Planning \&6 Control, 19, 379-396. doi:10.1080/09537280802034471.

Chou, Y.-C., Hsu, Y. S., \& Lin, H.-C. (2015). Installed base forecast for final ordering of automobile service parts. International Journal of Information and Management Sciences, 26, 13-28.

Chou, Y.-C., Hsu, Y. S., \& Lu, S.-Y. (2016). A demand forecast method for the final ordering problem of service parts. International Journal of Industrial Engineering: theory, Applications and Practice, 23, 108-118.

Cohen, M. A., Agrawal, N., \& Agrawal, V. (2006). Winning in the aftermarket. Havard Business Review, 84, 129-138.

Croston, J. D. (1972). Forecasting and Stock Control for Intermittent Demands. Operational Research Quarterly, 23, 289-303. doi:10.1057/jors.1972.50.

Dekker, R., Pinçe, Ç., Zuidwijk, R., \& Jalil, M. N. (2013). On the use of installed base information for spare parts logistics: A review of ideas and industry practice. International Journal of Production Economics, 143, 536-545. doi:10.1016/j.ijpe.2011.11.025.

Deshpande, V., Iyer, A. V., \& Cho, R. (2006). Efficient supply chain management at the US Coast Guard using part-age dependent supply replenishment policies. Operations Research, 54, 1028-1040. doi:10.1287/opre.1060.0327.

Dolgui, A., \& Pashkevich, M. (2008). Demand forecasting for multiple slow-moving items with short requests history and unequal demand variance. International Journal of Production Economics, 112, 885-894. doi:10.1016/j.ijpe.2007.07.008

Donnelly, J. M. (2013). The Case for Managing MRO Inventory. Supply Chain Management Review, 17, 18-25.

Fortuin, L. (1984). Initial supply and re-order level of new service parts. European Journal of Operational Research, 15, 310-319. 
Fortuin, L., \& Martin, H. (1999). Control of service parts. International Journal of Operations $\&$ Production Management, 19, 950-971. doi:10.1108/01443579910280287.

Furtak, S., Avital, M., \& Pedersen, R. U. (2015). Sensing the Future : Designing Predictive Analytics with Sensor Technologies. In ECIS 2015 Completed Research Papers.

Gharahasanlou, A. N., Ataei, M., Khalokakaie, R., Ghodrati, B., \& Jafarie, R. (2016). Tire demand planning based on reliability and operating environment. International Journal of Mining and Geo-Engineering, 50, 239-248. doi:10.22059/ijmge.2016.59875.

Ghobbar, A. A., \& Friend, C. H. (2002). Sources of intermittent demand for aircraft spare parts within airline operations. Journal of Air Transport Management, 8, 221-231. doi:10. 1016/S0969-6997(01)00054-0.

Ghobbar, A. A., \& Friend, C. H. (2003). Evaluation of forecasting methods for intermittent parts demand in the field of aviation: A predictive model. Computers and Operations Research, 30, 2097-2114. doi:10.1016/S0305-0548(02)00125-9.

Ghodrati, B. (2011). Efficient Product Support Optimum and Realistic Spare Parts Forecasting. In Replacement Models with Minimal Repair (pp. 225-269). London: Springer. doi:10.1007/978-0-85729-215-5.

Ghodrati, B., Akersten, P.-A., \& Kumar, U. (2007). Spare parts estimation and risk assessment conducted at Choghart Iron Ore Mine: A case study. Journal of Quality in Maintenance Engineering, 13, 353-363. doi:10.1108/13552510710829452.

Ghodrati, B., Benjevic, D., \& Jardine, A. (2012). Product support improvement by considering system operating environment: A case study on spare parts procurement. International Journal of Quality \& Reliability Management, 29, 436-450. doi:10.1108/ 02656711211224875 .

Ghodrati, B., \& Kumar, U. (2005a). Operating environment-based spare parts forecasting and logistics: a case study. International Journal of Logistics Research and Applications, 8, 96-105.

Ghodrati, B., \& Kumar, U. (2005b). Reliability and operating environment-based spare parts estimation approach A case study in Kiruna Mine, Sweden. Journal of Quality in Maintenance Engineering, 11, 169-184. doi:10.1108/13552510510601366.

Gu, J., Zhang, G., \& Li, K. W. (2015). Efficient aircraft spare parts inventory management under demand uncertainty. Journal of Air Transport Management, 42, 101-109. doi:10. 1016/j.jairtraman.2014.09.006.

Güvenir, H. A., \& Erel, E. (1998). Multicriteria inventory classification using a genetic algorithm. European Journal of Operational Research, 105, 29-37.

Hellingrath, B., \& Cordes, A.-K. (2014). Conceptual approach for integrating condition monitoring information and spare parts forecasting methods. Production \& Manufacturing Research, 2, 725-737. URL: http://dx.doi.org/10.1080/21693277.2014.943431. doi:10.1080/21693277.2014.943431. 
Hong, J. S., Koo, H.-y., Lee, C.-s., \& Ahn, J. (2008). Forecasting service parts demand for a discontinued product. IIE Transactions, 40, 640-649. doi:10.1080/07408170701745337.

Hong, Y., \& Meeker, W. Q. (2013). Field-failure predictions based on failure-time data with dynamic covariate information. Technometrics, 55, 135-149. doi:10.1080/00401706. 2013.765324.

Hu, Q., Bai, Y., Zhao, J., \& Cao, W. (2015). Modeling spare parts demands forecast under two-dimensional preventive maintenance policy. Mathematical Problems in Engineering, 2015. doi:10.1155/2015/728241.

Hu, Q., Boylan, J. E., Chen, H., \& Labib, A. (2017). OR in spare parts management: A review. European Journal of Operational Research, 0, 1-20. doi:10.1016/j.ejor. 2017. 07.058 .

Hua, Z., Zhang, B., Yang, J., \& Tan, D. S. (2007). A new approach of forecasting intermittent demand for spare parts inventories in the process industries. Journal of the Operational Research Society, 58, 52-61.

Huiskonen, J. (2001). Maintenance spare parts logistics: Special characteristics and strategic choices. International Journal of Production Economics, 71, 125-133. doi:10.1016/ S0925-5273(00)00112-2.

Inderfurth, K., \& Mukherjee, K. (2008). Decision support for spare parts acquisition in post product life cycle. CEJOR, 16, 17-42. doi:10.1007/s10100-007-0041-z.

Jalil, M. N., Zuidwijk, R., Fleischmann, M., \& van Nunen, J. A. (2011). Spare parts logistics and installed base information. Journal of the Operational Research Society, 62, 442-457. doi: $10.1057 /$ jors. 2010.38 .

Jin, T., \& Liao, H. (2009). Spare parts inventory control considering stochastic growth of an installed base. Computers and Industrial Engineering, 56, 452-460. doi:10.1016/j.cie. 2008.07 .002 .

Jin, T., \& Tian, Y. (2012). Optimizing reliability and service parts logistics for a timevarying installed base. European Journal of Operational Research, 218, 152-162. doi:10. $1016 /$ j.ejor.2011.10.026.

Johnston, F. R., \& Boylan, J. E. (1996). Forecasting for items with intermittent demand. Journal of the Operational Research Society, 47, 113-121. doi:10.1057/palgrave.jors. 0470110 .

Kennedy, W., Patterson, J. W., \& Fredendall, L. D. (2002). An overview of recent literature on spare parts inventories. International Journal of Production Economics, 76 , 201-215. doi:10.1016/S0925-5273(01)00174-8.

Kim, T. Y., Dekker, R., \& Heij, C. (2017). Spare part demand forecasting for consumer goods using installed base information. Computers and Industrial Engineering, 103, 201-215. 
Kontrec, N. Z., Milovanovic, G. V., Panic, S. R., \& Miloševic, H. (2015). A ReliabilityBased Approach to Nonrepairable Spare Part Forecasting in Aircraft Maintenance System. Mathematical Problems in Engineering, 2015, 1-7.

Kontrec, N. Z., \& Stefan, P. (2017). Spare Parts Forecasting Based on Reliability. In System Reliability chapter 6. (pp. 113-127). Rijeka: InTech. doi:10.5772/intechopen.69608.

Kourentzes, N. (2013). Intermittent demand forecasts with neural networks. International Journal of Production Economics, 143, 198-206. doi:10.1016/j.ijpe.2013.01.009.

Lanza, G., Niggeschmidt, S., \& Werner, P. (2009). Optimization of preventive maintenance and spare part provision for machine tools based on variable operational conditions. CIRP Annals - Manufacturing Technology, 58, 429-432. doi:10.1016/j.cirp.2009.03.030.

Levén, E., \& Segerstedt, A. (2004). Inventory control with a modified Croston procedure and Erlang distribution. International Journal of Production Economics, 90, 361-367. doi:10.1016/S0925-5273(03)00053-7.

Liu, X., \& Tang, L. C. (2016). Reliability analysis and spares provisioning for repairable systems with dependent failure processes and a time-varying installed base. IIE Transactions, 48, 43-56. doi:10.1080/0740817X.2015.1055391.

Lu, X. C., \& Hjelle, H. M. (2016). A new model for evaluating the volume of laptop spare parts depending on users' intentions related to laptop use time. International Journal of Simulation Modelling, 15, 181-193. doi:10.2507/IJSIMM15(1)C05.

Lu, X.-C., \& Wang, H.-N. (2015). The Laptop Spare Parts Studying under Considering Users' Repair Willingness. International Journal of Simulation Modelling, 14, 158-169. doi:10.2507/I JSIMM14(1)C04.

Mahlamäki, K., Borgman, J., Rämänen, J., Tuovinen, J., Finne, M., Perminova, O., Tiihonen, J., \& Öhman, M. (2016). Elements of installed base information value. In 22nd ICE/IEEE International Technology Management Conference (p. 7).

Minner, S. (2011). Forecasting and Inventory Management for spare Parts: An Installed Base Approach. In N. Altay, \& L. A. Litteral (Eds.), Service Parts Management chapter 8. (pp. 157-169). London: Springer. doi:10.1007/978-0-85729-039-7. arXiv:arXiv:1011.1669v3.

Pennings, C. L. P., van Dalen, J., \& van der Laan, E. A. (2017). Exploiting elapsed time for managing intermittent demand for spare parts. European Journal of Operational Research, 258, 958-969. doi:10.1016/j.ejor.2016.09.017.

Perminova-Harikoski, O., Tiihonen, J., Ohman, M., Finne, M., \& Kuusela, J. (2015). Installed Base Information Utilisation in Industrial Service Development and Operations. In M. Martinsuo, O. Perminova-Harikoski, \& T. Turunen (Eds.), Strategic Change towards Future Industrial Service Business chapter 1. (pp. 6-21). Tampere: Tampere University of Technology, Department of Industrial Management. 
Petrovic, D., \& Petrovic, R. (1992). SPARTA II : Further development in an expert system for advising on stocks of spare parts. International Journal of Production Economics, 24 , 291-300.

Poppe, J., Basten, R. J. I., Boute, R. N., \& Lambrecht, M. R. (2017). Numerical study of inventory management under various maintenance policies. Reliability Engineering and System Safety, 168, 262-273. doi:10.1016/j.ress.2017.06.012.

Qarahasanlou, A. N., Barabadi, A., Ataei, M., \& Einian, V. (2017). Spare part requirement prediction under different maintenance strategies. International Journal of Mining, Reclamation and Environment, 0930, 1-14. doi:10.1080/17480930.2017.1373883.

Rego, J. R., \& Mesquita, M. A. (2011). Spare parts inventory control: a literature review. Produção, 21, 655-665. doi:10.1590/S0103-65132011005000002.

Richey, R. G., Morgan, T. R., Lindsey-Hall, K., \& Adams, F. G. (2016). A global exploration of Big Data in the supply chain. International Journal of Physical Distribution 6 Logistics Management, 46, 710-739. doi:10.1108/IJPDLM-05-2016-0134.

Ritchie, E., \& Wilcox, P. (1977). Renewal theory forecastting for stock control. European Journal of Operational Research, 1, 90-93.

Romeijnders, W., Teunter, R., \& Van Jaarsveld, W. (2012). A two-step method for forecasting spare parts demand using information on component repairs. European Journal of Operational Research, 220, 386-393. doi:10.1016/j.ejor.2012.01.019.

Schultz, C. R. (1987). Forecasting and Inventory Control for Sporadic Demand Under Periodic Review. Journal of the Operational Research Society, 38, 453-358. doi:10.2307/ 2582735 .

Shaunty, J. A., \& Hare Jr, V. C. (1960). An Airline Provisioning Problem. Management Technology, 1, 66-84.

Si, X.-s., Zhang, Z.-X., \& Hu, C.-H. (2017). An adaptive Spare Parts Demand Forecasting Method Based on Degradation Modeling. In Data-Driven Remaining Useful Life Prognosis Techniques chapter 15. (pp. 405-417). Berlin: Springer.

Snyder, R. D. (2002). Forecasting sales of slow and fast moving inventories, European Journal of Operational Research, . European Journal of Operational Research, 140, 684-699.

Stormi, K., Laine, T., Suomala, P., \& Elomaa, T. (2018). Forecasting sales in industrial services: Modeling business potential with installed base information. Journal of Service Management, 29, 277-300. doi:10.1108/JOSM-09-2016-0250.

Syntetos, A. A. (2001). Forecasting of intermittent demand. Ph.D. thesis Brunel University.

Syntetos, A. A., \& Boylan, J. E. (2001). On the bias of intermittent demand estimates. International Journal of Production Economics, 71, 457-466. doi:10.1037/h0026857. 
Syntetos, A. A., \& Boylan, J. E. (2005). The accuracy of intermittent demand estimates. International Journal of Forecasting, 21, 303-314. doi:10.1016/j.ijpe.2010.07.005.

Syntetos, A. A., Boylan, J. E., \& Disney, S. M. (2009a). Forecasting for inventory planning: a 50-year review. Journal of the Operational Research Society, 60, 149-161. doi:10.1057/ jors.2008.173.

Syntetos, A. A., Nikolopoulos, K., Boylan, J. E., Fildes, R., \& Goodwin, P. (2009b). The effects of integrating management judgement into intermittent demand forecasts. International Journal of Production Economics, 118, 72-81. doi:10.1016/j.ijpe.2008.08.011.

Teunter, R. H., \& Fortuin, L. (1999). End-of-life service. International Journal of Production Economics, 59, 487-497.

Teunter, R. H., Syntetos, A. A., \& Babai, M. Z. (2011). Intermittent demand: Linking forecasting to inventory obsolescence. European Journal of Operational Research, 214, 606-615. doi:10.1016/j.ejor.2011.05.018.

The Economist (2017). Data is giving rise to a new economy. URL: https://www.economist.com/news/briefing/ 21721634-how-it-shaping-up-data-giving-rise-new-economy.

Wagner, S. M., \& Lindemann, E. (2008). A case study-based analysis of spare parts management in the engineering industry. Production Planning and Control, 19, 397-407. doi:10.1080/09537280802034554.

Wang, W., \& Syntetos, A. A. (2011). Spare parts demand: Linking forecasting to equipment maintenance. Transportation Research Part E, 47, 1194-1209. doi:10.1016/j.tre.2011. 04.008 .

Wang, X., \& Petropoulos, F. (2016). To select or to combine? The inventoryperformance of model and expert forecasts. International Journal of Production Research, 54, 5271-5282. doi:10.1002/2014GB005021, arXiv:1512.00567.

Willemain, T. R., Smart, C. N., \& Schwarz, H. F. (2004). A new approach to forecasting intermittent demand for service parts inventories. International Journal of Forecasting, 20 , 375-387. doi:10.1016/S0169-2070(03)00013-X.

Yamashina, H. (1989). The Service Parts Control Problem. Engineering Costs and Production Economics, 16, 195-208.

Zhong, R. Y., Newman, S. T., Huang, G. Q., \& Lan, S. (2016). Big Data for supply chain management in the service and manufacturing sectors : Challenges, opportunities, and future perspectives. Computers and Industrial Engineering, 101, 572-591. doi:10.1016/ j.cie.2016.07.013. 


\begin{tabular}{|c|c|c|}
\hline Paper & Evaluation & Results / comparison \\
\hline Ritchie \& Wilcox & Case study & Good graphical fit with real demand \\
\hline Fortuin $(1984)$ & Case study & $25 \%$ stock reduction / current policy \\
\hline Ghodrati \& Kumar (2005b) & Case study & $\begin{array}{l}\text { Difference in forecasted demand of } 20 \% \text { / covari- } \\
\text { ates not included }\end{array}$ \\
\hline Ghodrati \& Kumar (2005a) & Case study & $\begin{array}{l}\text { Difference in forecasted demand of } 40 \% \text { / covari- } \\
\text { ates not included }\end{array}$ \\
\hline Deshpande et al. (2006) & Empirical study & $\begin{array}{l}\text { Average inventory cost reduction of } 20 \% \text { / exoge- } \\
\text { nous lead time demand }\end{array}$ \\
\hline Ghodrati et al. (2007) & Case study & $\begin{array}{l}\text { Greater economical/production losses for non- } \\
\text { inclusion of covariates }\end{array}$ \\
\hline Hua et al. (2007) & Case study & $\begin{array}{l}\text { Lower error ratio, percentage error / SES, CR, } \\
\text { bootstrapping }\end{array}$ \\
\hline Hong et al. (2008) & Graphical analysis & $\begin{array}{l}\text { Better fit with real demand / Ritchie \& Wilcox } \\
(1977)\end{array}$ \\
\hline Jin \& Liao (2009) & Numerical example & $\begin{array}{l}\text { Inventory control system is sensitive to time-to- } \\
\text { failure distribution }\end{array}$ \\
\hline Ghodrati (2011) & Sensitivity analysis & $\begin{array}{l}\text { Exp. time-to-failure distribution more affected by } \\
\text { covariates than Weibull }\end{array}$ \\
\hline Jalil et al. (2011) & Case study & $\begin{array}{l}\text { Cost improvement of } 1-16 \% \text { for small and } 1-58 \% \\
\text { for large installed base / current policy }\end{array}$ \\
\hline Minner $(2011)$ & Simulation & Average inventory reduction of $50 \%$ / SES \\
\hline Wang \& Syntetos (2011) & Simulation & Reduced MAD / SBA \\
\hline Barabadi (2012) & Case study & $\begin{array}{l}\text { Influence of time-dependence of covariates on } \\
\text { spare part demand }\end{array}$ \\
\hline Ghodrati et al. (2012) & Implementation & $\begin{array}{l}\text { Less downtime and increased efficiency when con- } \\
\text { sidering covariates }\end{array}$ \\
\hline Jin \& Tian (2012) & Simulation & Validation of the method \\
\hline Romeijnders et al. $(2012)$ & Case study & $\begin{array}{l}\text { MSE and MAD reduced up to } 20 \% / \mathrm{CR}, \mathrm{SES} \text {, } \\
\text { Moving Average (MA), TSB }\end{array}$ \\
\hline Hong \& Meeker (2013) & Simulation & Reduced MSE when applying use-rate data \\
\hline Barabadi et al. (2014) & Case study & $\begin{array}{l}\text { hazard rate up to } 1.8 \text { times higher in different } \\
\text { operating conditions }\end{array}$ \\
\hline Hellingrath \& Cordes (2014) & Case study & Reduced forecast error / SBA \\
\hline Chou et al. $(2015)$ & Case study & MAD improves $16 \%$ / other regression models \\
\hline Hu et al. $(2015)$ & Case study & Influence of usage rates on spare part demand \\
\hline Kontrec et al. $(2015)$ & Case study & No validation/evaluation \\
\hline Lu \& Wang (2015) & Simulation & No significant difference / simulated demand data \\
\hline Chou et al. $(2016)$ & Case study & MAD improvements of $14,27 \%-51,5 \%$ / MA \\
\hline Gharahasanlou et al. (2016) & Case study & $\begin{array}{l}50 \% \text { difference in Economic Order Quantity and } \\
\text { order point when considering covariates }\end{array}$ \\
\hline Liu \& Tang 2016 & Numerical example & Inventory performance is robust \\
\hline Lu \& Hjelle (2016) & Simulation & No significant difference / simulated demand data \\
\hline Kim et al. (2017) & Case study & $\begin{array}{l}\text { Relative error, MAPE and RMSPE reduced by } \\
\text { factor } 2 \text { / AR model }\end{array}$ \\
\hline Kontrec \& Stefan (2017) & Case study & No validation/evaluation \\
\hline Qarahasanlou et al. (2017) & Case study & $\begin{array}{l}\text { Difference in forecasted demand / covariates are } \\
\text { not included }\end{array}$ \\
\hline Si et al. $(2017)$ & Case study & Forecasted and actual demand match well \\
\hline Stormi et al. $(2018)$ & Case study & Symmetric MAPE reduces $8 \% / \mathrm{CR}$ \\
\hline
\end{tabular}

Table 11: Overview of the validation/evaluation of the proposed forecasting method and main results 


\section{Paper}

Shaunty \& Hare Jr $(1960)$

Ritchie \& Wilcox (1977)

Fortuin (1984)

Yamashina (1989)

Petrovic \& Petrovic (1992)

Ghodrati \& Kumar (2005b)

Ghodrati \& Kumar (2005a)

Deshpande et al. (2006)

Ghodrati et al. (2007)

Hua et al. (2007)

Hong et al. (2008)

Jin \& Liao (2009); Jin \& Tian

(2012)

Lanza et al. (2009)

Ghodrati (2011)

Jalil et al. (2011)

Minner (2011)

Wang \& Syntetos (2011)

Barabadi (2012)

Ghodrati et al. (2012);

Barabadi et al. (2014);

Gharahasanlou et al. (2016)

Romeijnders et al. $(\sqrt{2012})$

Hong \& Meeker (2013)

Hellingrath \& Cordes (2014)

Chou et al. (2015)

Hu et al. (2015)

Kontrec et al. (2015)

Lu \& Wang (2015)

Chou et al. (2016)

Liu \& Tang (2016)

Lu \& Hjelle (2016)

Kim et al. (2017)

Kontrec \& Stefan (2017)

Qarahasanlou et al. (2017)

Si et al. (2017)

Stormi et al. (2018)

\section{Main contribution}

Link spare part demand to product usage

Forecast for the EOL phase and include replacement probability

Consider the initial supply of a part

Incorporate both new product sales and discards

(1) Link forecasts with inventory, (2) develop decision support software

Consider Weibull Time-To-Failure (TTF) distribution with environmen-

tal factors

Consider exponential TTF distribution with environmental factors

Link part-demand database with maintenance database

Perform risk analysis of ignoring environmental factors in forecasts

Include maintenance policy in forecasts

Model decreasing fleet size with part replacement probability

Model new product sales process

Include load-dependency in reliability analysis

Investigate different time-to-failure distributions with covariates Spatially (dis)aggregate traditional forecasts

(1) Develops method applicable in full PLC, (2) Forecasts distribution instead of point forecast

Use inspection-based delay time model for forecasts

Investigate impact of time-dependent covariates

Implement method of Ghodrati \& Kumar (2005a)

Differentiate between maintenance demand and part demand

Propose forecasts based on product use instead of calendar time

Integrate condition monitoring information and demand forecasts

Investigate impact of recency versus quantity of historical data

Incorporate two-dimensional (usage time and calender time) Preventive

Maintenance cycle in forecasts

Determine demand based on total unit time

Include repair willingness based on previous breakdowns

Demand probability increases for some parts in EOL phase

Consider dependencies between sub-failure processes in a system

Extend repair willingness concept

Investigate different types of installed base information

Consider data availability

Validate use of time-dependent covariates in case study

Integrate condition monitoring information with distributional forecasts

Use installed base information to manage customer lifetime value

Table 12: Main contributions of the selected literature 


\section{Paper}

Shaunty \& Hare Jr (1960)

Ritchie \& Wilcox (1977)

Fortuin (1984)

Yamashina (1989)

Petrovic \& Petrovic (1992)

Ghodrati \& Kumar

(2005b a); Ghodrati (2011);

Ghodrati et al. (2012);

Barabadi et al. (2014)

Deshpande et al. (2006)

Ghodrati et al. (2007)

Hua et al. (2007)

Hong et al. (2008)

Jin \& Liao 2009); Jin \& Tian (2012)

Lanza et al. (2009)

Jalil et al. (2011)

Minner (2011)

Wang \& Syntetos (2011)

Barabadi (2012)

Romeijnders et al. (2012)

Hong \& Meeker (2013)

Hellingrath \& Cordes (2014)

Chou et al. (2015)

Hu et al. (2015)

Kontrec et al. (2015)

Lu \& Wang (2015); Lu \&

Hjelle (2016)

Chou et al. (2016)

Gharahasanlou et al. (2016)

Liu \& Tang (2016)

Kim et al. (2017)

Kontrec \& Stefan (2017)

Qarahasanlou et al. (2017)

Si et al. (2017)

Stormi et al. (2018)

\section{Limitations/difficulties}

Empirical determination of usage weight per product necessary.

Do not model decrease of the installed base.

(1) Initial parameter estimates necessary, (2) not applicable in other PLC phases.

Hard to estimate product lifetime.

Poor accordance of failure rates from databanks with real conditions of use. Definition and estimation of covariates necessary.

Difficult to merge maintenance database with demand database.

Estimation of event-tree probabilities necessary.

Sufficient historical failures necessary for regression.

(1) Estimation of replacement probability needed, (2) not applicable in other PLC phases.

(1) Computationally challenging when not using exponential TTF distribution, (2) only consider increase of number of installs.

Estimation of load-dependent reliability function necessary.

Case dependent results do not necessarily hold in different setting.

Complicated method for forecasting $>1$ periods ahead.

Difficult to capture Delay-time parameters in practice.

(1) Definition and estimation of covariates necessary, (2) complex to consider many time-dependent covariates together.

Separate forecast for number of repaired components is hard if they fail rarely.

Assumptions necessary to generate predictions for non-connected parts.

(1) Sensors need to be present in all machines, (2) limited case study (5 parts, 1 period ahead)

(1) Estimation of combined replacement-discard probability necessary.

Estimation of relation usage-time and calendar-time necessary.

No evaluation/validation of method performance.

(1) Estimates of user repair willingness necessary, (2) conclusions not necessarily true for capital goods.

(1) Estimate of combined replacement-discard probability necessary, (2) many data observations necessary for valid regression.

Definition and estimation of covariates necessary.

Estimation of covariates for sub-failure process dependencies necessary.

(1) Long estimation period during production phase necessary, (2) preferably short EOL phase, (3) part deterioration depend on product age.

No validation/evaluation of the method performance.

Definition and estimation of covariates necessary.

Consider only 1 installed item.

(1) Over-forecasting bias present, (2) only consider fleet size (not age).

Table 13: Limitations of the studied work 